\title{
Microbiota e conservação de produtos frescais
}

\author{
Felipe de Lima Franzen', Janine Farias Menegaes ${ }^{2}$, Daiane Palma Cielo ${ }^{3}$, Giane Magrini Pigatto ${ }^{4}$, Tatiane Codem Tonetto ${ }^{5}$ \\ Mari Silvia Rodrigues de Oliveira ${ }^{6}$
}

Resumo - Os produtos frescais têm importância significativa no âmbito da qualidade e da segurança dos alimentos em função de suas características, especialmente por sua maior suscetibilidade à deterioração e a consequente curta vida útil para consumo. Assim, o objetivo deste trabalho foi realizar uma revisão bibliográfica apresentando os aspectos de interesse relacionados à microbiota e à conservação de produtos frescais. Para a presente pesquisa foram realizadas revisões bibliográficas nas literaturas nacional e internacional. Realizou-se uma busca por termos como microbiologia, microbiota, produtos frescais, produtos cárneos, produtos lácteos e conservação de produtos crus. A microbiota apresenta-se bastante variável, principalmente em função da espécie animal a partir da qual se obtém o produto ou a matéria-prima para elaboração de produtos derivados frescais. Já os processos de conservação incluem ações no sentido do impedimento de que os microrganismos cheguem ao produto; da destruição dos microrganismos e da modificação nas condições ambientais que impeçam o crescimento microbiano. Nesse sentido, os esforços acerca da obtenção de maior qualidade microbiológica nos produtos frescais devem alcançar toda a cadeia produtiva e a conservação dos produtos frescais pode complementar a melhoria das condições de viabilidade para seu consumo.

Termos para indexação: qualidade de alimentos; microbiologia de alimentos; deterioração de alimentos.

\section{Microbiota and conservation of fresh products}

\begin{abstract}
Fresh products are significantly important in terms of food quality and safety, due to the characteristics of these products, their susceptibility to deterioration and the consequent short shelf life for consumption. Thus, the objective of this work was to carry out a bibliographic review presenting the aspects of interest related to the microbiota and conservation of fresh products. For the present research, bibliographic reviews were carried out in the national and international literature. A search was carried out for terms microbiology, microbiota, fresh products, meat products, dairy products and raw product conservation. The microbiota is quite variable, mainly depending on the animal species from which the product or raw material is obtained to produce fresh products. Conservation processes, on the other hand, include actions to prevent microorganisms from reaching the product; destruction of microorganisms and changes in environmental conditions that prevent microbial growth. In this sense, efforts on obtaining higher microbiological quality in fresh products must reach the production chain, and the conservation of fresh products can complement the improvement of viability conditions for their consumption.
\end{abstract}

Index terms: food quality; food microbiology; deterioration of food.

\section{Introdução}

A temática acerca da microbiota e da conservação de produtos frescais se insere no âmbito da qualidade de alimentos sinalizando sua repercussão econômica, no que tange o aproveitamento de matérias-primas, particularmente de origem animal; cultural, considerando a difusão de seu consumo pela população, como no caso das chamadas linguiças frescais; e na própria saúde humana, em função da maior suceptibilidade desses produtos à deterioração microbiana, com potencial impacto aos consumidores (SIMÕES \& KORDIAK, 2016; KASPER et al., 2017; NUNES et al., 2019).
No Brasil a linguiça é um dos produtos cárneos mais fabricados, provavelmente porque sua elaboração, além de não exigir tecnologia sofisticada, utiliza poucos equipamentos, que são de baixo custo (TERRA, 1998; COLOMBO et al., 2016; NUNES et al., 2019).

Nesse contexto, a vida de prateleira - caracterizada por Forsythe (2013)

Recebido em 17/4/2020. Aceito para publicação em 19/8/2020.

${ }^{1}$ Engenheiro-agrônomo, M.Sc., Doutorando do Programa de Pós-Graduação em Alimentos e Nutrição, Faculdade de Engenharia de Alimentos, Universidade Estadual de Campinas - Unicamp, Rua Monteiro Lobato, 80 - CEP 13083-862 Cidade Universitária "Zeferino Vaz", Barão Geraldo, Campinas - SP, e-mail: ffranzen2@gmail.com

${ }^{2}$ Engenheira-agrônoma, Dr.a , Programa de Pós-Graduação em Agronomia, Centro de Ciências Rurais - CCR, Universidade Federal de Santa Maria - UFSM, Avenida Roraima, 1000, Prédio 70, Departamento de Fitotecnia, Cidade Universitária, Bairro Camobi, CEP 97.105-900, Santa Maria, RS, e-mail: janine_rs@ hotmail.com

${ }^{3}$ Nutricionista, M.Sc., Programa de Pós-Graduação em Ciência e Tecnologia dos Alimentos, CCR/UFSM, Avenida Roraima, 1000, Prédio 42, Departamento de Tecnologia e Ciência dos Alimentos, Cidade Universitária, Bairro Camobi, CEP 97.105-900, Santa Maria, RS, e-mail: daiane_cielo@hotmail.com

${ }^{4}$ Médica-Veterinária, Dr.ạ, Programa de Pós-Graduação em Ciência e Tecnologia dos Alimentos, CCR/UFSM, e-mail: gipigatto@yahoo.com.br

${ }^{5}$ Química-Industrial, M.Sc., Programa de Pós-Graduação em Ciência e Tecnologia dos Alimentos, CCR/UFSM, e-mail: tatytonetto@yahoo.com.br

${ }^{6}$ Farmacêutica Bioquímica, Dr.a, Docente do Departamento de Tecnologia e Ciência dos Alimentos - DTCA, CCR/UFSM, e-mail: marisilviadeoliveira@yahoo. com.br 
como o tempo que se passa desde a produção e a embalagem do produto até o ponto em que ele se torna inaceitável para o consumo - está relacionada com parâmetros intrínsecos e extrínsecos desse produto e apresenta-se, portanto, como um aspecto diretamente associado à microbiota e à conservação de produtos frescais (GERMANO \& GERMANO, 2015; KASPER et al., 2017).

Tanto o leite e seus derivados quanto a carne e seus derivados, devido à riqueza em nutrientes e a fatores como atividade de água $\left(a_{w}\right)$ e $\mathrm{pH}$, tornam-se meios adequados para o crescimento de grande variedade de microrganismos que chegam ao produto aleatoriamente (FRANCO \& LANDGRAF, 1996; JAY, 2005; ORDÓÑEZ et al., 2005).

A contaminação de queijos frescais por patógenos de origem alimentar, por exemplo, pode ocorrer ao longo das várias etapas da sua elaboração. Assim, para o controle preventivo da qualidade dos diferentes tipos de queijos, devem-se conhecer as principais fontes de patógenos e os mecanismos pelos quais podem ingressar na cadeia produtiva destes laticínios (ALMEIDA FILHO \& AZEVEDO, 2019). De acordo com Kasper et al. (2017), os produtos derivados do leite, entre eles os queijos, por serem perecíveis, devem ser produzidos com matéria-prima de boa qualidade e submetidos a um eficiente controle em todas as etapas de processamento. São as chamadas boas práticas de fabricação, que iniciam com a sanidade do rebanho, passam pela ordenha, a conservação do leite e vão até o produto final, incluindo as práticas dentro do laticínio, como o armazenamento, o transporte e a comercialização adequada, a fim de se evitar as toxinfecções alimentares para a população.

Portanto, o emprego das técnicas de conservação apresenta-se como contraponto à deterioração microbiana dos produtos frescais. Mas segundo Ordóñez (2005), deve-se considerar a maioria dos métodos empregados na conservação de alimentos como seletivos, já que não afetam igualmente todos os tipos de microrganismos presentes e, consequentemente, só agem aumentando a vida útil, como no caso da refrigeração ou do acondicionamento a vácuo. Assim, delimitando-se duas abordagens, uma sobre a microbiota associada aos produtos frescais cárneos, leites e alguns de seus derivados, e a outra sobre a conservação destes (CDC, 2016; KASPER et al., 2017).

Dessa forma, o objetivo deste trabaIho foi realizar uma revisão bibliográfica apresentando os aspectos de interesse relacionados à microbiota e à conservação de produtos frescais.

\section{Materiais e métodos}

Para a presente pesquisa foram realizadas revisões bibliográficas na literatura nacional e internacional, utilizando quatro bases de dados bibliográficas PubMed, Web of Science, Scielo e periódicos Capes. Foram também utilizados dados disponibilizados pela Agência Nacional de Vigilância Sanitária (Anvisa). Ao finalizar as pesquisas, as referências duplicadas foram excluídas. Realizouse uma busca por termos como microbiologia, microbiota, produtos frescais, produtos cárneos, produtos lácteos e conservação de produtos crus. O período de busca foi de março de 2017 a março de 2020. Foram selecionadas pesquisas, artigos ou trabalhos publicados em inglês, português ou espanhol.

\section{Microbiota relacionada aos produtos frescais cárneos \\ de aves e pescados}

As principais fontes de contaminação de carnes frescas por microrganismos referem-se à faca de sangria, pele do animal, trato gastroinstestinal, mãos dos manipuladores, recipientes, ambiente de manuseio e aos nódulos linfáticos destes animais. $O$ armazenamento prolongado em temperatura de refrigeração $\left(4^{\circ} \mathrm{C}\right)$ não é eficiente para inibir o desenvolvimento microbiano. Com isso, várias bactérias poderão comprometer a qualidade da carne pelo início da sua deterioração, como por exemplo, pelo Clostridium perfringens, uma bactéria Gram-positiva que apresenta a conformação de bacilo pertencente à família Clostridiaceae (JAY, 2005; SOARES \& GONÇALVES, 2012; FORSYTHE, 2013).

Em pescados a microbiota aquática advinda do gelo de conservação, dos barcos e da qualidade da água na captura do processo de pesca são as responsáveis pela conservação inicial dos produtos (GERMANO \& GERMANO, 2015; SOARES \& GONÇALVES, 2012; FORSYTHE, 2013).

Segundo Jay (2005), os gêneros de bactérias mais frequentemente encontrados em carnes frescas (bovina, suína e de aves) incluem: Acinetobacter, Aeromonas, Campylobacter, Corynebacterium, Enterococcus, Listeria, Micrococcus, Moraxella, Pseudomonas, Psychrobacter e Vagococcus. Dentre os gêneros de fungos, nos relatos mais frequentes de ocorrência em carnes frescas e refrigeradas, apontam-se: Cladosporium; Geothricum; Mucor; Rhizopus; Sporothricum e Thamnidium. Dentre as leveduras, destaca-se a ocorrência de Candida, Debaryomyces, Rhodotorula e Torulopsis em carnes frescas e refrigeradas.

Já em relação aos pescados, os de água morna tendem a ter uma microbiota mais rica em bactérias mesófilas Gram-positivas do que peixes de água fria, que apresentam mais bactérias Gram-negativas. Deste modo, os pescados marinhos são colonizados principalmente por psicotróficos (Pseudomonas ssp., Alteromonas ssp., Shewanella putrefaciens, Actinobacter ssp. e Moraxella ssp.), enquanto a microbiota mesófila constitui-se, geralmente, por micrococos e corineformes, além de Actinobacter (SOARES \& GONÇALVES, 2012; FORSYTHE, 2013; GERMANO \& GERMANO, 2015).

Os embutidos cárneos frescos são aqueles produtos preparados à base de carne crua, não submetidos a processos de cozimento, secagem ou outro tratamento térmico, sem o uso de aditivos e com período de consumo entre um a seis dias (BRASIL, 2019). Esses produtos devem ser conservados sob refrigeração (máximo de $4^{\circ} \mathrm{C}$ ) até o consumo, para assegurar a qualidade microbiológica (ORDÓÑEZ et al., 2005; SANTOS, 2016; NUNES et al., 2019).

Nesse sentido, destaca-se que, nas indústrias brasileiras (salsicharias e frigoríficos), as carnes bovina, suína e avícola são as mais utilizadas como matéria-prima na elaboração de produtos cárneos. O maior objetivo da industrialização da carne visa aumentar a vida útil, desenvolver diferentes sabores e 
utilizar partes do animal de difícil comercialização quando no estado fresco (TERRA, 1998; COLOMBO et al., 2016; NASCIMENTO et al., 2017).

Segundo o Decreto no 9.013 de 2017, Art. 297 "linguiça é o produto cárneo obtido de carnes cominuídas das diferentes espécies animais, condimentado, com adição ou não de ingredientes, embutido em envoltório natural ou artificial e submetido a processo tecnológico específico" (BRASIL, 2017).

A linguiça frescal caracteriza-se como um produto cru que não sofre nenhum tratamento térmico que reduza a sua microbiota, possui elevada atividade de água, tendo então uma vida-útil curta, a qual está diretamente ligada à carga microbiana resultante das diferentes contaminações, apesar da utilização do frio como ambiente de conservação (SANTOS, 2016; NUNES et al., 2019).

Segundo Daguer et al. (2011) e Colombo et al. (2016), produtos cárneos crus, como as linguiças frescais, frequentemente podem veicular microrganismos patogênicos em virtude da contaminação da matéria-prima, condimentos e/ou por manipulação inadequada e não serem submetidos a nenhum processo de cocção, propiciando o desenvolvimento de células vegetativas, como a Salmonella spp.

Daguer et al. (2011) verificaram em amostras de linguiças frescais, a contaminação de 3,8\% (51 amostras analisadas) por Salmonella spp. e a contagem de coliformes termotolerantes acima do previsto na legislação (103NMP $\mathrm{mL}^{-1}$ ) foram observadas em três amostras de salsicha $(1,5 \%)$ de um total de 23 amostras. Na presente pesquisa, a contaminação das salsichas pode ter ocorrido após o processo de cozimento, pelo processo manual de descasque, indicando práticas deficientes de higiene pelos manipuladores nos estabelecimentos fabricantes.

Produtos cárneos crus, como as linguiças frescais, frequentemente podem veicular microrganismos patogênicos em virtude da contaminação da matéria-prima, condimentos e/ou manipulação inadequada e, por não serem cozidos, não permitem a destruição de células vegetativas (GEORGES et al., 2019).

Conforme Instrução Normativa $n^{\circ}$ 60 , de 23 de dezembro de 2019, que estabelece as listas de Padrões Microbiológicos para Alimentos, os microrganismos patogênicos que devem ser pesquisados em embutidos crus (linguiças frescais) para verificar sua qualidade são Salmonella spp., Escherichia coli e aeróbios mesófilos (BRASIL, 2019).

Ainda no enfoque dos produtos frescais cárneos, assume destaque a carne moída, assim comercializada ou considerada como base para a fabricação de hambúrgueres, almondêgas e quibes. Conforme Jay (2005) a carne moída apresenta um número maior de microrganismos do que a carne não moída. Contribui para este fato a manipulação excessiva, os vários cortes utilizados e sua maior superfície de contato, o que favorece o crescimento de bactérias aeróbias, que frequentemente causam deterioração em baixas temperaturas, somados à utilização de moedores e utensílios sem adequada higienização. No mesmo sentido, cabe destacar que, em relação à incidência de microrganismos em carnes frescas de aves, a ave inteira tende a ter uma contagem microbiana mais baixa do que a ave em pedaços (GEORGES et al., 2019).

Nos pescados, a formação de uma camada limosa na pele caracteriza a presença de bactérias $\left(10^{2}-10^{5} \mathrm{UFC} \mathrm{g}^{-1}\right)$, nas brânquias $\left(10^{3}-10^{4} \mathrm{UFC}^{-1}\right)$ e nos intestinos $\left(10^{2}-10^{9} \mathrm{UFC}^{-1}\right)$ (FORSYTHE, 2013).

\section{Microbiota relacionada aos produtos frescais lácteos}

No leite a contaminação microbiana pode ocorrer diretamente pelo gado leiteiro (bovino, caprino, ovino, entre outros) para o leite, ou indiretamente pela contaminação do leite durante o processo de ordenha, armazenamento e transporte. Os patógenos transmitidos pelo leite se originam do próprio animal, do homem ou de contaminação a partir do ambiente. Manipuladores infectados, que não respeitam a higiene das mãos, também se constituem em fonte potencial de contaminação do leite. Durante a ordenha e transporte, o leite pode ser sujeito a contaminações pelos equipamentos e/ou pelo abuso do binômio tempo-temperatura, que criam condições ótimas para o cresci- mento microbiano (MOTARJEMI et al., 2014; PINTO et al., 2015; GEORGES et al., 2019).

A contaminação microbiana afeta negativamente a qualidade do leite, interferindo no processo de industrialização, reduzindo a durabilidade do leite fluido e de seus derivados lácteos (GERMANO \& GERMANO, 2015; ALMEIDA FILHO \& AZEVEDO, 2019).

O queijo fresco por definição é o produto que está pronto para consumo logo após sua fabricação. Nesse contexto, destacam-se os produtos lácteos frescais como o queijo minas frescal e a ricota. O queijo minas frescal é definido como "o queijo fresco obtido por coagulação enzimática do leite com coalho e/ou outras enzimas coagulantes apropriadas, complementada ou não com ação de bactérias lácticas específicas" e é classificado como "um queijo semigordo, de muito alta umidade, a ser consumido fresco" (BRASIL, 2004).

Já a massa da ricota é extraída do soro pela ação de calor que age sobre a fonte de ácido que causa a precipitação das proteínas. Ambos devem ser consumidos o mais próximo possível de sua data de fabricação, porque a transformação bioquímica e a degradação gradual de seus componentes orgânicos se iniciam imediatamente após sua produção (LIMA \& PENNA, 2012).

Desta maneira, nos primeiros momentos após a fabricação, a ação conjugada de enzimas naturais (lipases e proteases) e a microbiota produtora de ácido láctico (Streptococcus lactis e Streptococcus cremoris) são os responsáveis pelo aroma e sabor agradáveis destes produtos (PERRY, 2004; GEORGES et al., 2019).

Por outro lado, dependendo das condições de conservação, em virtude da intensa atividade lipolítica ou proteolítica dos microrganismos deteriorantes, em poucos dias pode-se verificar alterações ou defeitos nas características organolépticas (textura, cor, aroma, sabor, entre outros) destes produtos. Alguns tipos de queijos podem até mesmo apresentar massas heterogêneas ou oleaduras desejáveis devido ao gás produzido por microrganismos propiônicos anaeróbios ou indesejáveis, como as produzidas pelos coliformes (PINTO et al., 2015; NASCIMENTO et al., 2017). • 
É importante salientar que a qualidade da matéria-prima, o leite utilizado desde a ordenha, o armazenamento e o transporte até o laticínio, incluindo seu constante monitoramento através de indicadores de acidez, contagens bacterianas e de células somáticas, têm impacto direto no padrão e no prazo de validade dos queijos frescos (PERRY, 2004; PINTO et al., 2015).

Da mesma forma, a especificação e a qualidade dos diversos agentes coadjuvantes e ingredientes utilizados interagem com a matéria-prima no processo de fabricação dos diversos tipos de queijos, influenciando assim no produto final. Conforme Ducati \& Nespolo (2010), o oxigênio do ar é igualmente importante na acidificação dos produtos frescais, cuja maturação é essencialmente superficial e, por este motivo, devem ser consumidos em poucos dias, após abertas as embalagens.

Os contaminantes Listeria monocytogenes, Staphylococcus aureus, Salmonella spp., Escherichia coli e Mycobacterium avium subespécie paratuberculosis (MAP) são os principais causadores de doenças em humanos por contaminação de origem alimentar através do consumo de vários tipos de queijos (SPRICIGO et al., 2008; ALMEIDA FILHO; AZEVEDO, 2019). A contagem de Staphylococcus aureus e Escherichia coli em queijos com umidade igual ou acima de $46 \%$ não pode ser maior que $10^{3} \mathrm{UFC}$ $\mathrm{g}^{-1}$. Caso esse limite seja maior ou superior em qualquer etapa da elaboração desse produto, seu consumo torna-se inapropriado (PINTO et al., 2015; BRASIL, 2019; GEORGES et al., 2019).

\section{Conservação de produtos frescais}

Para estender a vida útil dos alimentos frescos faz-se necessário atuar contra os agentes de deterioração que podem ser físicos (temperatura), químicos (oxigênio) e microbiológicos (microrganismos), que promovem a deterioração de distintas formas. De acordo com Ordóñez (2005) e Kasper et al. (2017), para que os organismos possam alterar determinado alimento, é preciso que entrem em contato com ele e que aí se multipliquem. A partir daí, cabem ações para impedir que os microrganismos cheguem ao produto, uma delas fundamentalmente, com tratamentos térmicos ou pela modificação das condições ambientais, criando-se outras que impeçam o crescimento microbiano.

As embalagens destinadas ao acondicionamento de produtos cárneos devem proteger os produtos da luz, a qual fornece energia, que acelera a reação de oxidação, podendo resultar na perda de cor, vitaminas e valor nutritivo (JU et al., 2019; MOHAMED; EL-SAKHAWY \& EL-SAKHAWY, 2020). Devem ainda atuar como barreira ao vapor de água, evitando desta forma que os produtos ganhem ou percam água, pois quanto maior for a atividade de água, maior será a capacidade de deterioração por microrganismos (KALPANA et al., 2019).

As embalagens devem possuir propriedades de barreira a gases, como as embalagens a vácuo, onde o oxigênio é removido, ou embalagens com atmosfera modificada, que utilizam uma mistura de gases $\left(\mathrm{O}_{2}, \mathrm{CO}_{2}\right.$ e $\left.\mathrm{N}_{2}\right)$ que atuam inibindo o desenvolvimento microbiano (PANDEY et al., 2020; SHARMA et al., 2020).

Quando a carne é embalada a vácuo ou é usada uma atmosfera modificada com mais de $20 \%$ de $\mathrm{CO}_{2}$, e o crescimento de Pseudomonas spp. é suprimido. Sob estas condições as bactérias lácticas (LAB) crescem mais rapidamente (Lactobacillus, Carnobacterium e Leuconostoc) e são frequentemente os únicos organismos detectáveis durante a armazenagem refrigerada de produtos em atmosfera modificada (KURUWITA et al., 2020; PANDEY et al., 2020).

A utilização do vácuo é fundamental para alguns produtos, uma vez que o oxigênio propicia o crescimento de microrganismos aeróbios, que deterioram o alimento e acarretam a rancidez das gorduras, alterando as características organolépticas (LIN et al., 2020; LIU et al., 2020).

A oxidação lipídica constitui um fator preocupante no processamento de produtos embutidos, principalmente de linguiças, pois o consumo de produtos rançosos causa inúmeros problemas à saúde do consumidor (KURUWITA et al., 2020; PANDEY et al., 2020; SHARMA et al., 2020).

Duarte \& Gräff (2016) analisaram a contaminação microbiológica em linguiça frescal armazenada sob refrigeração por 45 dias e comprovaram que, independente da embalagem usada (MRP, Nylon, EVOH ou polietileno), a cor e o odor do produto alteram-se com o tempo. Na pesquisa, a contaminação por bactérias lácticas foi similar, independentemente do tipo de embalagem, aumentando no 14 o dia. Em relação às Pseudomonas spp, observou-se que no 3 o dia a contaminação para todos os tipos de embalagens ficou em $10^{2}$, e zerou no 140 dia de análise. E as amostras analisadas não apresentaram contaminação por Staphylococcus aureus, em nenhuma das embalagens, durante todo o experimento (45 dias).

Tratamentos térmicos sob alta pressão, congelamento, irradiação ou com a redução da atividade de água abaixo de valores de aproximadamente 0,6 detêm totalmente o crescimento microbiano ou eliminam todos os microrganimos viáveis. Em geral, não se utilizam os métodos de conservação de forma isolada, mas sim associados a outros (ORDÓÑEZ et al., 2005; GERMANO \& GERMANO, 2015).

Conforme a Resolução RDC no 272 (BRASIL, 2019) utilizam-se como conservantes em produtos cárneos processados frescos, nitrito de potássio e de sódio (máximo 0,015 g/100 g), nitrato de sódio e de potássio (máximo 0,03 g/100 g), diacetato de sódio e diacetato ácido de sódio (máximo 0,1 g/100 g).

O nitrito é um composto essencial dos aditivos usados para a cura da carne e confere a cor rosa e o sabor únicos à carne. $O$ óxido nítrico reage com a mioglobina $\left(\mathrm{Fe}^{2+}\right)$ e a metamioglobina $\left(\mathrm{Fe}^{3+}\right)$ para desenvolver uma cor rosa curada (ALAHAKOON et al., 2015).

O óxido nítrico se combina com a mioglobina $\left(\mathrm{Fe}^{2+}\right)$ para formar nitrosomioglobina, que é instável e o calor a converte em um pigmento rosa estável, denominado nitrosil-hemocromo. $\mathrm{O}$ nitrito atua como um antioxidante contra a oxidação de lipídios e inibe o crescimento de deterioração e bactérias patogênicas, incluindo Clostridium botulinum e Listeria monocytogenes (COLOMBO et al., 2016; NASCIMENTO et al., 2017).

Na perspectiva de melhorar a qualidade microbiológica dos pescados 
aponta-se que o número de bactérias do muco e da pele dos peixes podem ser reduzidos se o pescado for lavado, mas tanto o número como as espécies de bactérias que infectam o pescado vão influenciar na sua decomposição, já que há grande variação no seu comportamento no que se refere à capacidade de causar deterioração (SOARES \& GONÇALVES, 2012).

Por sua vez, considerando-se a conservação dos produtos frescais lácteos, assumem destaque as normativas referentes à matéria-prima leite, ressaltando-se sua importância na qualidade microbiológica dos produtos frescais a serem elaborados. No Brasil, a Instrução Normativa no. 76 dispõe sobre o critério microbiológico do leite pasteurizado e do leite pasteurizado tipo A cujo parâmetro de Enterobacteriaceae é de um limite máximo de $5 \mathrm{UFC} / \mathrm{mL}$. Ainda sobre a Instrução Normativa no. 76 sobre produção, identidade e qualidade de leite, após a ordenha, distinguem-se três categorias: "leite cru refrigerado; leite pasteurizado; e leite pasteurizado tipo A" (BRASIL, 2018).

Contudo, um leite de baixa qualidade microbiológica não se conserva por longos períodos, mesmo sob refrigeração, principalmente pela sua contaminação por bactérias psicrotróficas formadoras ou não de esporos, que produzem enzimas lipolíticas e proteolíticas que rapidamente alteram o produto (ALMEIDA FILHO \& AZEVEDO, 2019).

Esses grupos de microrganismos presentes no leite podem ser parcial e/ou quase que totalmente eliminados pelos processos de pasteurização e/ ou esterilização comercial. No entanto, esses processos podem não eliminar as enzimas termorresistentes de alguns microrganismos que provocam a coagulação doce do leite, por exemplo, que é um problema grande para a indústria. A destruição de grupos patogênicos torna o leite mais seguro, eliminando potenciais riscos de infecção, mas não corrige defeitos relacionados ao sabor, à composição ou à adequação para a industrialização (LORENZETTI, 2006; SPRICIGO et al., 2008).

Por fim, considera-se a necessidade de que, cada vez mais, os métodos de conservação em produtos frescais se- jam empregados de modo satisfatório. Segundo Picinin (2003) a elevada população bacteriana é indesejável para o consumidor, pois coloca em risco sua saúde devido à maior probabilidade de veiculação de doenças, muitas vezes, de alta patogenicidade. Para a indústria, o excesso de bactérias acarreta problemas na estocagem e no processamento dos alimentos e produtos que apresentam características sensoriais indesejáveis.

\section{Considerações finais}

Os produtos frescais apresentam sua inerente perecibilidade e a potencial contaminação microbiana, sobretudo a partir das suas matérias-primas, como aspectos desafiadores à garantia de qualidade e segurança ao consumidor. Nesse sentido, primordialmente, o investimento na obtenção de maior qualidade microbiológica nesses produtos deve alcançar toda a cadeia produtiva, desde a produção, o transporte e o processamento. Em relação à conservação dos produtos frescais, os esforços devem ser no emprego de técnicas adequadas e, como complemento, na meIhoria das condições de viabilidade para consumo desses produtos.

\section{Referências}

ALAHAKOON, A.U.; JAYASENA, D.D.; RAMACHANDRA, S.; JO, C. Alternatives to nitrite in processed meat: Up to date. Trends in Food Science \& Technology, v.45 n.1, p.37-49, 2015.

ALMEIDA FILHO, N.; AZEVEDO, L.L.T. Segurança alimentar e nutricional na América do Sul e BRICS: avanços e "nuvens" no horizonte. Economia e Sociedade, Campinas, v.28, n.3, p.717-739, 2019.

BRASIL. Ministério da Agricultura, Pecuária e Abastecimento. Instrução Normativa no 76, de 26 de novembro de 2018. Dispõe sobre Regulamentos Técnicos que fixam a identidade e as características de qualidade que devem apresentar o leite cru refrigerado, o leite pasteurizado e o leite pasteurizado tipo A. Brasília, DF, 2018.

BRASIL. Ministério da Agricultura, Pecuária e
Abastecimento. Decreto no 9.013, de 29 de março de 2017. Dispõem sobre a inspeção industrial e sanitária de produtos de origem animal. Brasília, DF, 2017.

BRASIL. Ministério da Saúde/Agência Nacional de Vigilância Sanitária. Instrução Normativa $n^{\circ}$ 60, de 23 de dezembro de 2019. Estabelece as listas de padrões microbiológicos para alimentos. D.O.U., Publicado em: 26/12/2019, Edição: 249, Seção: 1, p.133. Brasília, DF, 2019.

BRASIL. Ministério da Saúde. Agência Nacional de Vigilância Sanitária. RDC no 272, de 14 de março de 2019. Estabelece os aditivos alimentares autorizados para uso em carnes e produtos cárneos. D.O.U., Publicado em: 18/03/2019, Edição: 52, Seção: 1, p.194. Brasília, DF, 2019.

BRASIL. Ministério da Agricultura, Pecuária e Abastecimento. Instrução Normativa no 4, de 1 de março de 2004. Regulamento técnico para fixação de identidade e qualidade do queijo minas frescal. Brasília, D.O.U., 05 de março de 2004. Brasília, DF, 2004.

CDC. What is CDC's role in food safety? Centro de Controle e Prevenção de Doenças, 2016.

COLOMBO, S.G.; BACHINI, T.V.; SILVA, J.M. Modelo de Gestão para Otimização do Rendimento de Envoltórios Naturais na Fabricação de Linguiça Suína Tipo Frescal. Revista Latino Americana de Inovação e Engenharia de Produção, v.4, n.5, p.124-139, 2016. DOI: http://dx.doi.org/10.5380/relainep. v4i5.38383

DAGUER, H.; SILVA, H.D.; HIGASHIYAMA, E.R.; ZANETTE, C.M.; BERSOT, L.S. Qualidade de produtos cárneos fabricados sob Inspeção Federal no Estado do Paraná. Ciência Animal Brasileira, Goiânia, v.1 2, n.2, p.359364, 2011.

DUARTE, D.A.; GRÄFF, T.B.A. Influência de diferentes tipos de embalagens na estabilidade de linguiça frescal. Higiene Alimentar, v.30, n.260/261, p.109-115, 2016.

DUCATI, C.; NESPOLO, C.R. Queijo Minas e Ricota, semelhantes, mas não iguais. Jornal Sul Brasil, Chapecó, 02 set., 2010. p.25-25

FORSYTHE, S.J. Microbiologia da segurança dos alimentos. 2.ed. Porto Alegre: Artmed, 2013. 607p. 
FRANCO, B.D.G.M.; LANDGRAF, M. Microbiologia dos Alimentos. São Paulo: Atheneu, 1996. p.27-28.

GEORGES, S.O.; BERNARDO, L.G.; ANDRÉ, M.C.D.P.B.; CAMPOS, M.R.H.; BORGES, L.J. Ecofisiologia microbiana e micro-organismos contaminantes de linguiça suína e de frango do tipo frescal. Boletim do Centro de Pesquisa de Processamento de Alimentos, Curitiba, v.36, n.1, 2019.

GERMANO, P.M.L.; GERMANO, M.I.S. Higiene e vigilância sanitária de alimentos: qualidade das matérias-primas, doenças transmitidas por alimentos, treinamento de recursos humanos. [S.I: s.n.], 2015. 1077p.

JAY, J.M. Microbiologia de alimentos. 6. ed. Porto Alegre: Artmed, 2005. 711p.

JU, J.; CHEN, X.; XIE, Y.; YU, H.; GUO, Y.; CHENG, Y.; QIAN, H.; YAO, W. Application of essential oil as a sustained release preparation in food packaging, Trends in Food Science \& Technology, v.92, p.22-32, 2019. https://doi.org/10.1016/j.tifs.2019.08.005.

KALPANA, S.; PRIYADARSHINI, S.R.; LEENA, M.M.; MOSES, J.A.; ANANDHARAMAKRISHNAN, C. Intelligent packaging: Trends and applications in food systems, Trends in Food Science \& Technology, v.93, p.145157, 2019. DOI: https://doi.org/10.1016/j. tifs.2019.09.008.

KASPER, D.; FAUCI, A.; HAUSER, S.; LONGO, D.; JAMESON, J.; LOSCALZO, J. Manual de medicina de Harrison. 19. ed. Porto Alegre: AMGH, 2017. 1408p.

KURUWITA, D.P.; JIANG, X.; DARBY, D.; SHARP, J.L.; FRASER, A.M. Persistence of Escherichia coli 0157:H7 and Listeria monocytogenes on the exterior of three common food packaging materials, Food Control, v.112, p.107153, 2020. DOI: https://doi.org/10.1016/j. foodcont.2020.107153.

LIMA, M.S.; PENNA, L.P.C. Fabricação de Produtos Lácteos: Princípios Básicos. Belo Horizonte: Emater-MG, 2012. 68p.

LIN, W.; NI, Y.; PANG, J. Size effect-inspired fabrication of konjac glucomannan/polycaprolactone fiber films for antibacterial food packaging, International Journal of Biological Macromolecules, v.149, p.853-860, 2020. DOI: https://doi.org/10.1016/j.ijbiomac.2020.01.242.
LIU, C.; HUANG, J.; ZHENG, X.; LIU, S.; LU, K.; TANG, K.; LIU, J. Heat sealable soluble soybean polysaccharide/gelatin blend edible films for food packaging applications, Food Packaging and Shelf Life, v.24, p.100485, 2020. DOI: https://doi.org/10.1016/j. fpsl.2020.100485.

LORENZETTI, D.K. Influência do tempo e da temperatura no desenvolvimento de microrganismos psicrotróficos no leite cru de dois estados da região sul. 2006. 71f. Dissertação (Mestrado em Tecnologia de Alimentos) - Universidade Federal do Paraná, Curitiba, 2006.

MOTARJEMI, Y.; MOY, G.G.; JOOSTE, P.J.; ANELICH, L.E. Milk and Dairy Products. In: Yasmine Motarjemi and Huub Lelieveld (Ed.) Food Safety Management: Practical Guide for the Food Industry. Harmonização Global, Bilthoven, Holanda, 2014. p.83-117.

NASCIMENTO, R.S.; FONSECA, A.B.; FEIJÓ, M.B.S.; FRANCO, R.M.; MIRANDA, Z.B. Physicochemical characteristics of smoked cooked linguiças made with ostrich meat trimmings. Arquivo Brasileiro de Medicina Veterinária e Zootecnia. v.69, n.2, p.491-496, 2017. DOI: https://doi.org/10.1590/1678-4162-8969.

MOHAMED, S.A.A.; EL-SAKHAWY, M.; ELSAKHAWY, M.A.M. Polysaccharides, protein and lipid-based natural edible films in food packaging: A Review, Carbohydrate Polymers, v.238, p.116-178, 2020. DOI: https:// doi.org/10.1016/j.carbpol.2020.116178.

NUNES, L.P.S.; CARDOSO FILHO, F.C.; CALDAS, M.L.; MARTINS, L.M.; SANTOS, L.P.S.; MURATORI, M.C.S. Microbiologia de linguiças caseiras in natura, refrigeradas, assadas e congeladas. Ensaios e Ciencias, v.23, n.1, p.67-69, 2019.

ORDÓÑEZ, J.A. Tecnologia de alimentos. Componentes dos alimentos e processos. Vol. 1. Porto Alegre. Editora Artmed. 2005. 294 p.

ORDÓÑEZ, J.A.; MURAS, F.; JONG, E.V. Tecnologia de Alimentos - Alimentos de Origem Animal. Tradução de Fátima Murad. Porto Alegre: Artmed, v.2, 2005. 279p.

PANDEY, V.K.; UPADHYAY, S.N.; NIRANJAN, K.; MISHRA, P.K. Antimicrobial biodegradable chitosan-based composite nano-layers for food packaging, International Journal of
Biological Macromolecules, v.157, p.212219, 2020. DOI: https://doi.org/10.1016/j. ijbiomac.2020.04.149.

PERRY, K.S.P. Queijos: aspectos químicos, bioquímicos e microbiológicos. Quím. Nova, São Paulo, v.27, n.2, p.293-300, 2004.

PICININ, L.C.A. Qualidade do leite e da água de algumas propriedades leiteiras de Minas Gerais. 2003. 89f. (Mestrado em Medicina Veterinária) - Escola de Veterinária, Universidade Federal de Minas Gerais, 2003.

PINTO, C.L.O.; MACHADO, S.G.; MARTINS, M.L.; VANETTI, M.C.D. Identificação de bactérias psicrotróficas proteolíticas isoladas de leite cru refrigerado e caracterização do seu potencial deteriorador. Revista do Instituto de Laticínios Cândido Tostes, v.70, n.2, p.105, 3 set. 2015.

SANTOS, C.Y. Diagnóstico de situação da produção de linguiça fresca suína no Município de Rio Verde/GO. 2016. 93f. Tese (Doutorado) - Universidade Estadual Paulista, Faculdade de Ciências Agrárias e Veterinárias, Jaboticabal, 2016.

SHARMA, R.; JAFARI, S.M.; SHARMA, S. Antimicrobial bio-nanocomposites and their potential applications in food packaging, Food Control, v.112, 107086, 2020. DOI: https:// doi.org/10.1016/j.foodcont.2020.107086.

SIMÕES, P; KORDIAK, J. Avaliação da temperatura de gondolas da rede de frios de supermercados da cidade de Ponta Grossa- Pr. 2016. 32f. Trabalho de Conclusão de Curso (Tecnologia em alimentos) - Universidade Tecnológica Federal do Paraná. Ponta Grossa, 2016.

SOARES, K.M.P.; GONÇALVES, A.A. Qualidade e segurança do pescado. Revista Instituro Adolfo Lutz (Impr.), São Paulo, v.71, n.1, 2012.

SPRICIGO, D.A.; MATSUMOTO, S.R.; ESPÍNDOLA, M.L.; FERRA, S.M. Prevalência, quantificação e resistência a antimicrobianos de sorovares de Salmonella isolados de linguiça frescal suína. Ciência e Tecnologia de Alimentos, Campinas, v.28, n.4, p.779-785, 2008.

TERRA, N.N. Apontamentos sobre tecnologia de carnes. São Leopoldo: Editora Unisinos, 1998. p.59-87. 